\begin{abstract}
Locke's porphyry argument at 2.8.19 of the Essay has not been properly appreciated. On my reconstruction, Locke argues from the premise that porphyry undergoes a mere Cambridge change of color in different lighting conditions to the conclusion that porphyry's colors do not belong to it as it is in itself. I argue that his argument is not quite sound, but it would be if Locke chose a different stone, alexandrite. Examining his argument teaches us something about the relation between explanatory qualities and real alterations and something about the ways that colors inhere in bodies.
\end{abstract}

\title{
Cambridge Changes of Color
}

Michael Jacovides

\begin{abstract}
"But perhaps electricity changes their colour and they change back again in daylight?"

“That would be a queer kind of change, wouldn’t it?” says Jim.

"I suppose so," says bewildered John.
\end{abstract}

Wilfred Sellars

"Empiricism and the Philosophy of Mind"

\section{The Porphyry Argument}

A philosopher occasionally has the pleasure of finding an argument that improves with contemplation. I want to explain and evaluate an argument in the Essay Concerning Human Understanding that repays close attention particularly well. Locke asks us to 
consider the red and white colours in Porphyre: Hinder light but from striking on it, and its Colours Vanish; it no longer produces any such Ideas in us: Upon the return of Light, it produces these appearances on us again. Can anyone think any real alterations are made in the Porphyre, by the presence or absence of Light; and that those Ideas of whiteness and redness, are really in Porphyre in the light, when 'tis plain it has no colour in the dark? It has, indeed, such a Configuration of Particles, both Night and Day, as are apt by the Rays of Light rebounding from some parts of that hard Stone, to produce in us the Idea of redness, and from others the Idea of whiteness: But whiteness or redness are not in it at any time, but such a texture, that hath the power to produce such a sensation in us (2.8.19).

It is possible to read this passage so that it offers us either an unattractive argument or no argument at all. For instance, Martha Brandt Bolton $(1983,361,63)$ believes that this argument "turns on" the undefended, implicit, and "not entirely convincing" premise that "it is inconceivable that porphyry should have a property resembling the idea of red at the same time that its color has disappeared (i.e., it is not producing the idea of red)." Peter Alexander (1985, 126-27), on the other hand, believes that the passage contains no argument, only an example of the explanatory power of corpuscularianism.

Against these interpretations, I will argue that Locke presents us with an attractive argument that teaches us something about the relation between real changes and the ways that qualities inhere in bodies. I would reconstruct his premises as follows:

\section{Porphyry is red and white in the light.}

He does not say this in so many words but he wants us to consider the red and white colors in porphyry and says that they vanish when we obstruct the light. ${ }^{1}$

\footnotetext{
${ }^{1}$ In his introduction to his edition of the Essay A. D. Woozley $(1964,34)$ interprets Locke as saying that bodies are not colored at all. Those who agree with him will resist my interpretation of the first premise. I think that Woozley must be mistaken. Locke repeatedly characterizes secondary qualities as powers to produce ideas in us. (e.g. at 2.8.14, 15, 23, 24, and 26) For example, a fire's heat and color are its powers to produce the corresponding ideas. (2.23.7) Since fire manifestly does have these powers, it follows on his account that it is hot and red. In any case, the proper interpretation of this argument does not really turn on whether Locke believes that porphyry is ever, in any sense, red and white. Since everyone can agree that he believes that red and white do not belong to porphyry as it is in itself, such readers may treat his request for us to consider the red and white colors in porphyry as the hypothesis of a reductio argument: "Suppose that red and white colors belong to porphyry as it is in itself." I do not mind this reading at all. The conclusion I attribute to Locke will still follow. (I owe this alternative interpretation to Tony Martin.)
} 


\section{Porphyry is not red and white in the dark.}

Locke tells us that porphyry "has no colour in the dark." The third premise is

\section{Neither the presence nor the absence of light causes a real alteration in porphyry.}

This is the obvious assertoric content of the rhetorical question "Can anyone think any real

alterations are made in the Porphyre, by the presence or absence of light?"

You might think that Locke's premises contradict one another and conclude that we should cast about for an alternative reading. That would be a mistake; in the next section, I will explain how he can consistently believe that porphyry loses its colors in the dark without undergoing a real alteration.

Locke's premises are more evident than his conclusion. He implies that no reasonable person can believe that "those Ideas of whiteness and redness are really in Porphyre in the light" and tells us that "whiteness or redness are not in [porphyry] at any time." What do these statements mean?

There is more than one way of understanding Locke without running afoul of his intentions. ${ }^{2}$ I want to interpret him in light of a clue from his chapter on ideas of substance, where Locke asserts that

the greatest part of the Ideas, that make our complex Idea of Gold, are Yellowness, great Weight, Ductility, Fusibility, and Solubility, in Aqua Regia, etc. all united together in an unknown Substratum; all which Ideas, are nothing else, but so many relations to other Substances; and are not really in the Gold, considered barely in it self. (2.23.37)

He again writes of ideas being really in things, but this time he elaborates. The idea of yellowness is a relation, "not really in gold, considered barely in itself." At 2.25.10, Locke declares that "all Words, that necessarily lead the Mind to any other Ideas, than are supposed really to exist in that thing, to which the Word is applied, are relative Words" (2.25.10). We ought to be careful; Locke writes of 
what people suppose and not of what is, and he writes of words and not of qualities. Nevertheless, this passage confirms the reading suggested by the previous passage. If the idea of a quality is not really in a body, then the quality is somehow relational. When we combine this evidence with his characterization of an idea of a primary quality as one that gives us "an Idea of the thing, as it is in it self," (2.8.23) we are led to conclude that for Locke an idea really exists in a thing if the idea is associated with a quality that belongs to the thing as it is in itself.

On my reading, Locke's conclusion is

\section{Red and white do not belong to porphyry as it is in itself.}

One might wonder why Locke expresses this conclusion by using the words that he does. In particular, why does he bother to deny that "those Ideas of whiteness and redness are really in Porphyre in the light"? The porphyry argument occurs in a group of sections epitomized in the marginal summary by the line "Ideas of primary Qualities are resemblances; of secondary, not" and the whole chapter is entitled "Some farther Considerations concerning our simple Ideas". Locke expresses his conclusion idiosyncratically because of his interest in ideas and the ways they represent. He believes that ideas represent qualities in two ways. First, some ideas represent by being effects of objects. These ideas represent bodies as possessing a power to produce certain ideas in us, either directly or indirectly. Second, some ideas represent by being resemblances of qualities. These ideas, and only these ideas, can represent bodies as they are in themselves. If an idea resembles a quality in a body, then something very much like that idea resides in the body. Then, and only then, will Locke say that we have caught hold of an idea that represents a quality as it is in itself.

In the next section, I offer the beginnings of an account of real alterations and defend the validity of the porphyry argument. I begin the third section by explaining what porphyry is, and in

\footnotetext{
${ }^{2}$ I would not deny that he wants to refute the scholastic theory of perception with this argument or that he wants to
} 
that section and the next, I criticize Locke's premises but show that similar arguments, involving the colors of substances other than porphyry, are sound. That is to say, I show that his argument is not quite sound, but it would be, if he chose another rock.

\section{What are Real Alterations?}

Locke tells us that the red and white colors in porphyry vanish when less light strikes it; he also tells us that porphyry undergoes no "real alterations" because of the absence of light. In order to see the compatibility of these assertions, we would do well to start with a more modern discussion of real alterations. Peter Geach $(1969,71-72)$ asserts that

the only sharp criterion for a thing's having changed is what we may call the Cambridge criterion (since it keeps occurring in the Cambridge philosophers of the great days, like Russell and McTaggart): The thing called ' $\chi$ ' has changed if we have ' $\mathrm{F}(x)$ at time $t$ true and ' $\mathrm{F}(x)$ at time $t^{\prime \prime}$ false, for some interpretation of ' $\mathrm{F}$ ', ' $t$, and ' $t$ '

Here, Geach explains the Cambridge criterion in terms of an object's ceasing to satisfy an interpreted predicate. Elsewhere $(1972,321)$, he construes the Cambridge philosophers as explaining "change as simply a matter of contradictory attributes' holding good of individuals at different times." In the porphyry argument, Locke is more concerned with attributes and qualities than he is with predicates. For now, let me glide over the distinction between attributes and predicates and just say that according to the Cambridge criterion of change if something is an $\mathrm{F}$ at one time and is no longer an F at some other time, then that thing has changed. Geach $(1972,321$ 22) observes that

there is a sense of 'change', hard to explicate, in which it is false to say that Socrates changes by coming to be shorter than Theaetetus when the boy grows up, or that the butter changes by rising in price, or that Herbert changes by 'becoming an object of envy to Edith'; in these cases, 'Cambridge' change of an object (Socrates, the butter, Herbert) makes no 'real' change in that object.

show that colors are not 'real Beings' (to use a term from 2.31.2). 
Geach calls changes that meet the Cambridge criterion but are not real changes 'mere Cambridge changes' ${ }^{3}$

If Geach is onto a real distinction here-and I believe that he is—-we have an obvious way of resolving the alleged contradiction between Locke's premises that porphyry has red and white colors in the light, lacks them in the dark, and yet does not undergo any real change through the absence of light. These propositions can all be true if ceasing to be red and white is a mere Cambridge change in porphyry.

In order to evaluate Locke's argument, we need to get clearer on what mere Cambridge changes are. Let us return to Geach's examples, since they produce relatively strong intuitions. He says that the butter does not really change when its price goes up; presumably, he would agree that it does really change when it melts. How does becoming more expensive differ from melting so that the second but not the first is a real change? Melting is a physical change while becoming more expensive is merely an economic change. Someone might suggest that real changes are physical changes.

This suggestion will not work as it stands. Consider the change that befalls Socrates when Theaetetus becomes taller than him. Socrates has not really changed, according to Geach and according to me. ${ }^{4}$ However, the fact that Socrates has become shorter than Theaetetus is a physical fact since it concerns only the lengths of certain bodies. It follows that there is a sense in which becoming shorter than Theaetetus is a physical change that Socrates undergoes. Becoming shorter than Theaetetus in these circumstances is not, to be sure, a real physical change, but this is because it is not a real change, and that is just what we want to explain.

\footnotetext{
${ }^{3}$ I should point out that not all mere Cambridge changes are unimportant changes. Becoming a widower is a mere Cambridge change, but no one would deny its significance.

${ }^{4}$ Geach borrows the example from Plato, who seems to draw a similar conclusion. (Theaetetus, 155b-c.)
} 
Seventeenth century mechanical philosophers thought that the fundamental explanatory qualities were solidity, extension, figure, and motion. On a more modern list, electric charge, and other qualities would be added, while solidity would be dropped (at least on some construals of solidity). Let me borrow a term from Locke and call the aggregate of a body's fundamental explanatory qualities its 'internal constitution'. ${ }^{5}$ Whatever the true list of fundamental explanatory qualities turns out to be, I propose the following criterion of real changes. If a body undergoes a real change, it must meet the Cambridge criterion for change because it acquired different fundamental explanatory qualities. Call this the dependency thesis.

Let us return to Geach's examples. The price of butter changes due to the vagaries of supply and demand and not due to any change in the physical structure of any butter. In contrast, it loses its firmness because its internal constitution changes, that is, it has gained or lost fundamental explanatory qualities. ${ }^{6}$ Socrates will certainly change some of his fundamental explanatory qualities in the time it takes Theaetetus to grow taller than him. We might imagine that he gains ten kilograms, for example. Nevertheless, on the assumption that Socrates did not shrink while Theaetetus grew, Theaetetus is not now taller than Socrates because of any change in Socrates' internal constitution. In another example, Geach points out that timeless numbers undergo change according to the Cambridge criterion “whenever, e.g. five ceases to be the number of somebody's children." (Geach 1968, 72) If we may extend our thesis to mathematical entities, we have an

\footnotetext{
${ }^{5}$ I believe that my usage is faithful to Locke's but nothing turns on that. I stipulate that by the internal constitution of the thing, I mean the fundamental explanatory qualities of that thing considered independently of how the thing is sorted. Whether or not there is any sense in which the sciences are unified, I have in mind the fundamental explanatory qualities from the true physics.

${ }^{6}$ When I write that a body really alters because of a change in its internal constitution one might worry that the change in internal constitution must be a real change and that the resulting circularity vitiates the account. Not so. When I write of change in a body's internal constitution, I mean that the body gains or loses a fundamentally explanatory qualities, that is, that the body meets the Cambridge criterion of change with respect to one of its explanatory qualities
} 
explanation of why numbers never really change. They do not have changeable explanatory qualities.

I do not believe that Locke would accept the dependency thesis without qualification. ${ }^{7}$ At 4.3.6, Locke tells us that he sees no contradiction in supposing that God "should, if he pleased, give to certain Systems of created sensless matter, put together as he thinks fit, some degrees of sense, perception, and thought". What Locke means is a matter of controversy, ${ }^{8}$ but I take him to assert that God can take a suitably arranged piece of matter and annex qualities to it. That suggests that he believes that the targeted piece of matter can acquire intrinsic qualities such as being in pain by fiat, without changing its internal constitution.

We do not need to enter this controversy here. Since we may suppose that God does not intervene when we hinder the light from striking porphyry, and we may suppose that Locke does not believe that God intervenes on such a mundane occasion, we may limit ourselves to attributing a pious version of the dependency thesis to Locke: unless God intervenes, when a body undergoes a real change, it meets the Cambridge criterion for change because it acquired different fundamental explanatory qualities. For simplicity's sake, I will ignore this complication in what follows.

The unmodified dependency thesis provides a necessary condition for a object's really changing: if an object really changes then it meets the Cambridge criterion because of a change in the its internal constitution. Do all objects that meet the Cambridge criterion because of changes in their internal constitutions really change? No-not if we do not restrict what counts as dependence upon a change in internal constitution. Suppose that Herbert becomes the object of Edith's envy by doing a backflip. Even in these circumstances, I would say that becoming the object of Edith's envy is a mere Cambridge change in Herbert. Nevertheless, Edith's envy depends upon an action of

\footnotetext{
${ }^{7}$ In this paragraph, I am indebted to Eileen O’Neill.
} 
Herbert's and his action depends upon physiological changes inside his body. We thus have an example of a mere Cambridge change in which a person meets the Cambridge criterion of change because of changes in his internal constitution.

For evaluating Locke's third premise, it will turn out that the important thesis is that every time a body really changes it meets the Cambridge criterion because of a change in its internal constitution. Determining the exact nature of the dependence between a change in internal constitution and meeting the Cambridge criterion of change that suffices to make the change a real change is not crucial for my project.

Geach is onto an intuitive idea that I have attempted to explicate. I have attributed his notion of a real alteration to Locke because doing so makes Locke's arguments interesting and coherent. In fact, his porphyry argument is valid on this interpretation. As I said, Locke's premises add up to the thesis that porphyry ceases to be red and white in a mere Cambridge change when we hinder light from striking it. He concludes porphyry is not red and white as it is in itself. In order to establish the validity of Locke's argument, it will suffice to establish the following principle: if an object may lose a quality in a mere Cambridge change, then that quality does not belong to the object as it is in itself. Call this principle the Cambridge principle. Consider a quality that belongs to an object as it is in itself. If that object loses that quality, then I submit it really changes. If a feature belongs to a thing as it is in itself, then the thing cannot possibly lose the feature except by really changing. Therefore, if a feature may be lost in a mere Cambridge change, then that feature does not belong to the object as it is in itself. ${ }^{9}$

\footnotetext{
8 See Wilson(1979), Ayers (1981), Wilson (1982), McCann (1983), Milton (1983), Ayers (1991,vol. 2, chapter 12), McCann (1994, §3), Stuart (1996), Ayers (1997, 162-64), and Jacobs and McNeish (1997).

9 My analysis of Locke's porphyry argument is similar to Peter Sandøe's (1988) interpretation of Jonathan Bennett's (1968) phenol argument. This similarity is no coincidence, of course; Bennett explicitly connects the porphyry argument and the phenol argument and suggests "that the contrast I have drawn between primary and secondary qualities ... is one which Locke saw dimly and was struggling to express and defend" (Bennett 1968, 117-18). I want to travel in a path
} 
Suppose that Ernie believes that snakes are slimy until Bert informs him that they are not. When Ernie changes his mind, snakes lose the quality of being believed by Ernie to be slimy. Of course, snakes do not really change when he changes his mind any more than butter changes when its price goes up. By the Cambridge principle, it follows that being believed by Ernie to be slimy is not a quality that belongs to snakes as they are in themselves. If it were, then for snakes to lose the quality of being thought of by Ernie as slimy, Bert would have to really change the snakes, instead of just changing Ernie. Thus, the Cambridge principle offers us the right result in at least this particular case.

Notice that the Cambridge principle does not depend upon the dependency thesis or upon other considerations involving internal constitutions. The Cambridge principle only depends upon the metaphysical principle that any possible change of a quality that belongs to a thing as it is in itself would be a real change.

The Cambridge principle and principles like it have been around for a long time. A version this principle may be found in the Theaetetus: "Well now, supposing such things as size or warmth or whiteness really belonged to the object we measure ourselves against or touch, it would never be found that this object had become different simply by coming into contact with another thing and without any change in itself' (154b). Modern versions may be found in Smith (1973, 327), Lombard $(1986,97)$, and Sandøe $(1988,210)$. There are quibbles to be raised and distinctions to be drawn, but these quibbles and distinctions raise issues only tangentially related to Locke's argument. None endangers the validity of his inference. I will forgo the quibbles

\section{Various Colors of Various Things}

parallel to the one that Sandøe traveled before me. He uses the Cambridge principle in an analysis of a neo-Lockean argument and I want to use it in the analysis of a paleo-Lockean argument. Beyond that, our paths diverge. Sandøe 
Having endorsed the validity of Locke's argument, let me turn to an evaluation of its premises, beginning with the proposition that porphyry has no color in the dark. The thesis of this section is that though porphyry, like most objects, does not change colors in different lighting conditions, some objects do.

If we do not worry about what porphyry is, we will read the argument at 2.8 .19 as if it were general — that is, as if the reference to porphyry in the argument could be replaced by a reference to any other colored object. According to Samuel Rickless (1997), Locke assumes as a premise that no body possesses any color in the dark. Everything in a dark windowless room is colorless.

We do not ordinarily say that objects lose their colors in the dark; rather, we more naturally say that we cannot see the colors of objects in the dark. In fact, at the illumination levels at which color vision ceases to function, I would not even want to say that roses look black; rather, I would say that I cannot make out the color of roses.

Ordinary talk does not demonstrate that roses are red in the dark; conceivably, what we ordinarily say could be wrong. For all I have said, there may be an argument by which reason could take us by the neck and force us to concede that roses are colorless in the dark. Moreover, I would not argue that only a fool would think that all objects are colorless in the dark, and Locke was no fool. Rickless rightly warns of anachronism (1997, 303). Epicurus, Avicenna, Roger Bacon, and Isaac Newton all believed that objects had no color in the dark (Guerlac 1986), and none of them was a fool.

Our main concern in evaluating 2.8.19, however, is not with what Locke believes, but with how he argues. The general thesis that objects lack color in the dark would be a poor foundation for his argument. If we apply Locke's reasoning to roses, the result will not convince anyone who does

does not believe that there are any examples of mere Cambridge changes of secondary qualities. 
not already deny that colors belong to objects as they are in themselves (Rickless, 315). Before saddling him with an argument with no rhetorical force, we ought to know what porphyry is.

A rock has a porphyritic structure if it contains visible crystals inside a finer groundmass. Paradigmatically, the groundmass is purple or dark red. The word 'porphyry' comes from the Greek word for purple, but you should not think that porphyry is a vivid purple. Porphyry has faint red patches that can only be seen in good light at close proximity. In poor light or at a moderate distance, one cannot see any reddish color in the rock. At close range, one can see the larger crystals reflecting white light. This appearance also vanishes in dim light. Because of these phenomena, Locke concludes that porphyry has no such colors in the dark.

Let us consider the red in porphyry first. Is Locke's assertion any more plausible than the analogous premise that roses are not red in the dark? There is at least this difference: in dim light, porphyry looks dark gray. In fact, indoors at a distance of about ten feet the rock looks dark gray. Still, in spite of the fact that porphyry looks as if it were not reddish in dim light, my first instinct is to say that porphyry is reddish all the same. The fact that it does not look that way in all circumstances merely reveals the limits of our eyesight.

Since this instinct may be a prejudice, we should try to consider the issue from a $17^{\text {th }}$ century point of view. Scientific revolutionaries doubted that they should always study natural phenomena under natural conditions. Francis Bacon $(1620 / 1960,25)$, for example, asserted that "the nature of things betrays itself more readily under the vexations of art than in its natural freedom." This suspicion of natural conditions extended to natural viewing conditions; many of the great discoveries of the age were made with the microscope or the telescope. Boyle and Newton rejected natural light as the best illumination for all research when they recommended darkening the room before carrying out experiments with prisms (Guerlac, 19). 
Along these lines, Locke might criticize my opinion that porphyry has colors in the dark on the grounds that I show a scholastic bias in favor of natural lighting conditions. Such a criticism would be misguided. The crucial distinction is not between natural and artificial light or between standard and unusual light. Rather, the important distinction is between better and worse light. Prismatic spectra can be seen most easily in a darkened room, and their apparent saturation is greater. Ordinary non-luminous bodies are harder to see in the dark, and it is more difficult to make out their features. This last fact provides us with an explanation of why porphyry does not look red in the dark: there is not enough light for us to see that it is red. Locke needs to criticize the natural account of the phenomenon before assuming that porphyry loses its redness in the dark.

In 1830, a gemstone was discovered that would serve Locke's purposes better than porphyry. This stone, alexandrite, really does change color in different lighting conditions. Alexandrite, ruby, and emerald all interact with light in roughly the same manner (Nassau 1983, 89). A chromium impurity in an otherwise colorless background causes the color of all three gems.

Differences in the background electrical field surrounding the chromium bring about the dramatic differences in their colors. An electrical field that is weaker than the corresponding field in rubies, but stronger than the one in emeralds surrounds the chromium atoms in alexandrite. Alexandrite's spectral transmittance pattern is also intermediate between ruby's and emerald's. According to Kurt Nassau,

the resulting appearance is quite unexpected: in blue-rich daylight or the similar quality light from a fluorescent lamp ... we see an intense blue-green color, somewhat resembling emerald, while in red-rich candle light or the light from an incandescent lamp we perceive a deep red color, somewhat resembling a ruby .... . Nature has found a way of avoiding the almost impossible task of providing a color truly intermediate between the green of emerald and the red of ruby! (Ibid.) 
Nassau does not say it, but I will: alexandrite changes colors in different lighting conditions. ${ }^{10}$

With porphyry, the fact that we cannot see its reddish color in poor light does not show that it loses its redness in the dark; it only reveals the limitations of our eyesight. However, alexandrite appears differently in different good bright lights. Indoor lighting and outdoor lighting are both, in their own ways, standard lighting conditions, ${ }^{11}$ and there is no sense in saying that one of them is more appropriate for determining the color of alexandrite.

My dictionary disagrees with me. It describes alexandrite as "a grass-green chrysoberyl that shows red color by transmitted or artificial light." According to this description, alexandrite's true color is grass-green and it merely appears to be red in certain deviant conditions. On the other hand, according to the caption of the display of alexandrite at the American Museum of Natural History in New York, alexandrite "changes from green in daylight to red in artificial light." How should we adjudicate such a dispute?

At this point, it will help to divide predicates from qualities. Distinguish two questions: first, whether the predicate 'green' applies to alexandrite all the time, even in incandescent light and, second, whether there is a real quality green that inheres in alexandrite as it is in itself all the time. Believing in the meaningfulness of the predicate does not commit a philosopher to believing that there is a quality corresponding to it. Someone might adopt the view that W. V. Quine sympathetically describes in "On What There Is" $(1980,10)$, “the word 'red' or 'red object' is true of sundry individual entities which are red houses, red roses, red sunsets; but there is not, in addition, any entity whatever, individual or otherwise, which is named by the word 'redness'."

\footnotetext{
${ }^{10}$ Nassau is less guarded in his caption for color figure 21, where he describes alexandrite as "changing from a reddish color in the light from an incandescent lamp or a candle to a greenish color in daylight or the light from a fluorescent tube lamp."

${ }^{11}$ According to C. L. Hardin $(1988,73)$, the Commission Internationale de l'Éclairage "specifies a series of standard illuminants with controlled spectral characteristics, such as source A (incandescent lamp), source B (near sunlight) and source C (near daylight—-North Daylight' of the Munsell specification)."
} 
How the predicate 'green' works is a linguistic question that should be decided with the methods of a linguist. Are native English speakers, when apprised of the relevant physical, optical, and other non-linguistic facts about alexandrite, inclined to call it 'green' all the time, even indoors, when it looks red? I bet that they have no such inclination, though, of course, a systematic study of the question would appeal to surveys of the well informed and citations from their writings. The dictionary writers presumably relied upon at least a few of the latter, but, given the text of the museum display, we know that geologists do not universally use the word 'green' in that way.

Reasonable people may differ over the way our color language applies to alexandrite. Nevertheless, given the chemical and optical facts, it is implausible to think that there is a quality, green, that constantly belongs to alexandrite as it is in itself. We only have a reason to think that alexandrite possesses greenness all the time if we have a reason to think that only sunlight reveals the true color of alexandrite. However, on the assumption that the colors of alexandrite belong to it independently of observers and lighting conditions, we have no such reason. Undeniably, the sun is a natural light source and a light bulb is an artificial one, but some stars give off light that is qualitatively similar to a light bulb's. If we took an alexandrite gem near Antares, the gem would appear red. ${ }^{12}$ I say that it would be red. Alexandrite's appearance is a chemical compromise between the appearance of ruby and the appearance of emerald. Given the chemistry and the phenomena, it is arbitrary to assert that the resemblance to ruby that reddish light reveals is illusory and that the resemblance to emerald that bluish light reveals is real.

Someone might reply that our eyes work best in the light that the Sun provides, so what alexandrite would look like to us on distant planets is not to the point. Because we evolved on this

\footnotetext{
${ }^{12}$ It would probably look red. Although red giants look red and light bulbs do not, the latter are redder in the technical sense of having a lower color temperature. There are stars, called 'brown dwarves', with a color temperature similar to an ordinary incandescent light bulb. If alexandrite does not appear red near Antares, perhaps we could move the example near a brown dwarf. I am indebted in this footnote to Sarah Gibson.
} 
planet, the objector might continue, we detect real colors in sunlight. A creature with the analogue of eyes that evolved near Antares would detect real colors in antareslight.

Human eyes are indeed attuned to sunlight. We can distinguish the colors of some objects in sunlight that we cannot distinguish in incandescent light. Artificial light also allows us to distinguish the apparent colors of objects that seem to be the same color in sunlight, but these examples are less common (Hardin 1988, 73). Still, there is no survival value to classifying alexandrite with emeralds and apart from rubies with respect to color. Alexandrite has an unusual spectral reflectance pattern; this pattern yields appearances that are irrelevant to reproductive fitness. Thus, we should not expect that species on planets with different natural lighting conditions would judge that emeralds have the same color as alexandrite.

My argument that alexandrite is not green in incandescent light has been based on the assumption that, in sunlight, green belongs to alexandrite as it is in itself. If colors are not intrinsic features of bodies but instead depend upon standard observers or standard light conditions, then nothing I have said shows that alexandrite is not constantly green, even when it appears red. If colors of things somehow depended upon the nature of earthly animals, it would not be incredible if we could see alexandrite's colors rightly only in the light that we grew up in.

Someone who believes that green belongs to alexandrite as it is in itself will reject the possibility that its greenness depends on the way that terrestrial eyes work. On the hypothesis that green belongs to alexandrite as it is in itself, I hope to have shown that the light provided by our star is not epistemically better than the light provided by incandescent light. If we do not see alexandrite better in daylight than in incandescent light, then the natural thing to say is that alexandrite changes colors as its lighting conditions change. The present sub-conclusion is that if green belongs to alexandrite as it is in itself, then alexandrite changes color in different lighting conditions. By the 
end of the paper, I hope to show that the hypothesis that green belongs to alexandrite as it is in itself is untenable.

One could resist my sub-conclusion by using hyphens extravagantly. For example, someone could describe alexandrite as 'green-in-sunlight' (with hyphens between the words in the predicate) all of the time and also describe alexandrite as always 'not-green-in-incandescent-light'. Because no object can be red and green all over, an object must lose its greenness in order to become red. Therefore, in order to reject the conclusion that alexandrite changes color, one must block one of two inferences. The resister must either deny that 'c is-green-in-sunlight' and 'c is in sunlight' entails that 'c is green', or she must deny that ' $c$ is red-in-incandescent-light' and ' $c$ is in incandescent light' entails that 'c is red'. There is no logical difficulty in asserting that alexandrite is green-in-sunlight while denying that, in sunlight, alexandrite is green. Still, the position is awkward. If someone wants to deny that alexandrite changes color in different lighting conditions and wants to avoid the arbitrary preference between indoors and outdoors that I have criticized, she must reject both inferences, since she must reject one. Such rejections will lead the objector to the view that alexandrite is constantly green-in-sunlight and constantly red-in-incandescent-light but never simply green or simply red.

If the purpose of these contortions is to maintain that alexandrite has its color as it is in itself, even if the objector wins the battle, she will lose the war. The predicate is-red-inincandescent-light' wears its relation to external circumstances on its sleeve. Just as 'is the niece of Jane Fonda' describes the way a person is relative to another person, 'red-in-incandescent-light' describes the way a thing is relative to a circumstance. If the only colors that alexandrite has are the hyphenated colors green-in-sunlight and red-in-incandescent-light, then it does not have its colors as it is in itself; it only has its colors relative to its circumstances. 
The objector may reply that this response confuses predicate and quality; the predicate contains hyphens and refers to lighting conditions; the quality does not. On this view, 'green-insunlight' is a misleading term that denotes an intrinsic feature of bodies. I personally find it hard to believe that in ordinary English the predicate 'is green in sunlight' denotes a feature that belongs to bodies as they are in themselves.

In any case, if we dissociate these qualities from apparent colors considered in relation to particular lighting conditions, we lose our grip on what these qualities are. The proponents of such entities could fill in the details in a variety of ways. I will examine two possibilities. Once we admit that alexandrite has green-in-sunlight and red-in-incandescent light, some philosophers might assert that other bodies have pairs of distinct related colors. Consistency would push such philosophers to assert that emeralds have kindred qualities corresponding to these other hyphenated predicates, corresponding to different possible lighting conditions. They have green-in-sunlight, and they have green-in-incandescent-light. They may have as many colors as there are stars in heaven. We have only the slenderest grounds for believing in this multitude of colors. Alexandrite appears different in different lighting conditions. We can account for this phenomenon without multiplying mysterious colors.

Frank Jackson and Robert Pargetter's (1987) treatment of these issues suggests an alternative way of having hyphenated color predicates denote intrinsic properties. On their account, 'the greenness of $\mathrm{O}$ in circumstances $\mathrm{C}^{\prime}$ denotes the quality that causes $\mathrm{O}$ to look green in $\mathrm{C}$. For example, 'alexandrite's greenness-in-sunlight' might denote the quality of containing a certain amount of chromium ions in a certain background electrical field. Since that quality also makes alexandrite look red in incandescent light, this particular analysis has the unfortunate consequence of 
identifying alexandrite's greenness-in-sunlight with its redness-in-incandescent-light. ${ }^{13}$ I say that a quality of being green in some circumstance could never be identical to a quality of being red in some other circumstance, since green and red are different colors. Jackson and Pargetter accept that this sort of identification might occur (1987 135); this acceptance, I suppose, reflects their treatment of such properties as being green in sunlight as intrinsic features of things and not as relations to colors in circumstances. Their line of thought provides us with a sort of code, a mapping from hyphenated color predicates to physical properties. Although linguists would not invent this code and geochemists would not use it, it is justifiable and intelligible. Intelligible or not, this code cannot give us an account of the colors we see in alexandrite. So long as red is not green, the color we see in alexandrite indoors is not the color we see in alexandrite outdoors.

Let me return to porphyry and consider its whiteness. I am fairly confident that Locke has in mind the reflection of the light in the salient crystals. If that is what he means, then it does not seem that he can legitimately claim that the porphyry has changed colors when the light ceases to be reflected off the crystals. We almost never say that an object takes on the color of the light that it merely reflects.

In evaluating my last assertions, you need to keep in mind the distinction between scattering and reflection. Most of the light that bounces off most objects is scattered; it goes off in every direction, no matter from which angle the light came. However, some smooth surfaces reflect light. The light leaves the object on the same plane from which it came and follows a path such that the angle of reflection equals the angle of incidence. Reflection is responsible for most shininess and for what we see in the mirror.

\footnotetext{
${ }^{13}$ An alternative would be to identify alexandrite's greenness-in-sunlight with alexandrite's tendency to absorb little green light and its redness-in-incandescent-light with its tendency to absorb little red light, but this would make the properties dispositional relations to light. Given Nassau's explanation of the chemistry behind alexandrite's appearance,
} 
Generally speaking, reflection does not affect the color of objects. There is a white spot on the linoleum of my kitchen floor that moves as I pace, but there is no part of the linoleum that is white. Rather, my kitchen floor is pale yellow-green, brown, and blue-green, and I see all of these colors by the scattering of light. Likewise, if I stand in front of a mirror wearing a red shirt, I do nothing to make any part of the mirror red.

There is a counter-example to the principle that reflection does not determine the color of objects—namely, the sea. Since this counter-example, like alexandrite, provides a better example of a mere Cambridge change of color than porphyry does, we should examine it more carefully. Pure water is, of course, basically clear. Seawater is a little less clear, but the difference is not that seawater contains blue particles. A large quantity of water or ice will have a slight blue tint for internal reasons, but most of the blue color of the sea is a reflection of the sky (Hardin 1988, 4). If the sky is blue (and the water is relatively calm) then the sea will appear blue. If the sky is gray then the sea will appear gray. We should not think of the grayness of the sea as an illusion brought about by the fact that there is not enough light to see its true blueness. Rather, on cloudy days with calm water the sea is gray in just the same way as it is blue on sunny days. The color of the sea reflects the color of the sky.

At this point, you may be tempted to group the color of the sea with mirror images and glare spots and deny that the sea has any color beyond its residual blue tint. However, the sea, unlike a mirror, seems to have the same color to all normal observers from all angles above it. Perhaps we can best do justice to the intuition that the sea is not really blue by saying that blue does not belong to the sea as it is in itself. Still, this is consistent with saying that the sea is blue on calm clear days, which is, after all, what we do say.

I cannot think of a candidate intrinsic physical property that might be said to explain alexandrite's green appearance in sunlight but not its red appearance in incandescent light. 
To sum this section up: Locke is mistaken in asserting that porphyry has red and white colors in the light and no color when the light is hindered from striking the rock. The parts of porphyry are red all of the time though sometimes we cannot see this redness. In addition, the reflection of light off the salient crystals in porphyry never produces a white color in the porphyry. Even so, there are better examples to make the points that Locke wants to make. Alexandrite is green in daylight and not green in incandescent light. ${ }^{14}$ The sea is blue on clear days and not blue on gray days.

\section{Does the Alteration of Illumination Really Alter Visible Objects?}

In this section, I want to examine the third premise of my reconstruction of the porphyry argument, Locke's assumption that light causes no real alteration in porphyry. I also want to look at the analogous premises in the analogous arguments involving alexandrite and the sea.

As $I$ argued in $\$ 1$, a real alteration in a thing must depend upon an alteration in the internal constitution of that thing. One might think that Locke could just appeal to the intuition that light is too wispy to affect internal constitutions. However, when we think of phenomena that are well known to him such as the growth of plants, suntanning, and sun-bleaching, as well as his belief that light is composed of thousands of hard particles moving at very high speeds, our confidence that he can legitimately assume that light has no effect on visible objects dwindles.

We can see that these facts do not seriously endanger Locke's argument by focusing on the absence, rather than the presence, of light. If the reduction of light sufficed to change the color of porphyry, all that Locke would need for his argument to work would be to show that the reduction of light does not change the internal constitution of porphyry. Although one could come up with

\footnotetext{
${ }^{14}$ Or so say I. What I need to have shown for the purposes of the wider argument is that if, in daylight, alexandrite has
} 
possibilities in which porphyry changes its fundamental explanatory qualities in virtue of not being pelted by little light corpuscles, such situations are hard to think of and Locke may justifiably ignore them. If the cessation of light does not cause any change in the fundamental explanatory qualities of the porphyry, we may infer by the dependency thesis that the cessation of light does not really change the porphyry. Thus, I conclude, Locke is within his rights to assume that the cessation of light does not produce a real alteration in porphyry.

My analogous arguments involving alexandrite and the sea cannot work in the same way, since they depend upon a change of light and not merely upon a reduction of light. Given a more modern conception of optics, we know that the change of lighting leads to a real alteration in the objects since objects absorb energy when they absorb light. This alteration is perhaps greater for alexandrite than for seawater; but, though seawater does not absorb much sunlight, it does absorb some, and this is enough to alter its internal constitution.

Even so, as the example of Socrates and Theaetetus showed us in the second section, we merely need to show that the change of color does not depend upon any alteration of the porphyry's fundamental explanatory qualities; it does not matter if the change of color happens to coincide with a change in these qualities. In fact, the changes of color in alexandrite and the sea in different lighting conditions do not depend upon any change of internal constitution that they undergo. If alexandrite absorbed the same light in different good lighting conditions, but transmitted different patterns in just the way that it does now, then alexandrite would still change its color. Likewise, if alexandrite absorbed radically different light in different good lighting conditions, but always transmitted patterns of light that were similar to one another, then the stone would not change its

green as it is in itself, then, in incandescent light, alexandrite does not have green as it is in itself. 
color. The color of an object does not depend upon the light that stays inside of it; if it depends upon light at all, it depends upon the light that leaves it.

An objector might concede that much but reply that the ordinary transmission of light requires a change in the internal constitution of alexandrite; an electron must become excited by absorbing a photon and then emits a photon when it falls to a less excited state. ${ }^{15}$ The basic structure that is responsible for alexandrite's appearance (a chromium appearance in a chrysoberyl background) remains the same in all lighting conditions. The variation in alexandrite's internal structure is a bit like the variation in a curtain of hanging beads in a doorway when someone passes through. True, a person would not pass through if the beads did not give way, and true, a large person will displace a different pattern of beads than a small person. Nevertheless, I say, if a large person rather than a small person is transmitted through the doorway, this fact does not depend upon a change in the internal constitution of the curtain.

I thus conclude what may have been obvious to you from the beginning: the change of color in alexandrite and the sea does not depend upon a change in their fundamental explanatory qualities. By the dependency thesis, we may infer that these changes are mere Cambridge changes. It then follows by the Cambridge principle that alexandrite and the sea do not possess their colors as they are in themselves. ${ }^{16}$

At this point, let me contrast my conclusions with some remarks of G. E. M. Anscombe’s. In "The Subjectivity of Sensation" (1981), she observes that apparent color may vary depending upon its background. She considers a book cover that

shows two red squares traversed by stripes, which are green in one case while in the other they are blue. The red here and the red there look different, more so by daylight than by artificial light, and more so when looked at obliquely. The red of

\footnotetext{
${ }^{15}$ In this paragraph, I am indebted to Phillip Bricker and Lisa Shapiro.

${ }^{16}$ Of course, most changes of color are real changes. If a mailbox is painted red, then it really changes.
} 
the square traversed by green stripes looks almost or quite orange. But we say: nevertheless the two reds are identical, as you will see if you cover up the traversing stripes or look along the length of the stripes. Of course, the red is all one pigment. $(1981,46-47)$

To the question "why do we say that the reds are the same?" Anscombe replies

that there isn't exactly a reason, a justification. It is rather that our language just does go like that. Colours that keep on looking the same to the same eye, against the same backgrounds, and in the same light and orientation, are the same. That is to say, we regard the colour that things 'are' as not changed by these changes. $(1981,47)$

According to her, colors are not susceptible to mere Cambridge changes.

Anscombe's comments contradict the letter of Locke's porphyry argument, but not its spirit. She denies that a body could change colors without undergoing a real alteration, but she does not present this as a fact about the nature of surfaces — that their colors cling to them so tenaciously. Rather she presents it as a fact about language. She is not making a point about the quality red, as it resides on book covers or in porphyry; she is making a point about the predicate 'red' as it is used in English.

Locke might be somewhat sympathetic to Anscombe’s linguistic claim. After all, he complains at 2.31.2 that our way of talking about secondary qualities misleads us into thinking that secondary qualities are real beings in bodies. At 2.25.10, right after declaring that "Words, that necessarily lead the Mind to any other Ideas, than are supposed really to exist in that thing, to which the Word is applied, are relative Words," Locke classes 'black' along with 'man', 'merry', and 'extended' as 'absolute' words 'because they neither signify nor intimate any thing, but what does, or is supposed really to exist in the Man thus denominated." 'Black' is commonly thought to signify something some man, thus it is an absolute word. Locke does not mention here that he believes that this common thought is false. Language does not follow metaphysics; at best, it follows 
people's beliefs about metaphysics. Perhaps he would have conceded that, misleading though it might be, people sometimes do talk in the way that Anscombe says they do.

I think that Anscombe is mistaken, at least when it comes to alexandrite and the sea. She does not discuss these examples and it is not obvious what she would say when confronted with them. In any case, the metaphysical question does not hang on questions of ordinary language. If my reasoning has been sound, green never belongs to alexandrite as it is in itself, no matter what we say.

\section{Extrapolation}

As I have interpreted Locke's porphyry argument, his choice of porphyry matters a great deal, and it is not at all obvious that the argument can be generalized to the colors of other objects, let alone to all other secondary qualities. Surely, Locke does not intend to make a point that applies only to a particular kind of rock. How does his argument fit into the wider context of his discussion of primary and secondary qualities?

As I understand the structure of the middle of the chapter on primary and secondary qualities, in $\$ \int 11-18$, Locke offers a master argument intended to show that our ideas of colors, smells, tastes, and sounds do not resemble anything in bodies. In $\int \$ 19-21$, Locke offers illustrative examples to support his general argument; among these is his appeal to visual aspects of porphyry. Though these illustrative instances support and develop Locke's conclusion, he does not intend them to stand independently of his broader argument. ${ }^{17}$

Even if Locke does not intend his discussion of porphyry to be a freestanding argument for the conclusion that no color belongs to any object as it is in itself, we could try to turn it into one. 
The obvious way to do this would be by appealing to a uniformity principle. One might think that things could only have colors in one way: either all colors belong to things as they are in themselves or none of them belongs to anything as it is in itself. If porphyry is colored but not colored as it is in itself, it would follow that nothing is colored as it is in itself.

However, I am not sure that we have any reason to believe in a uniformity principle of this sort, especially such a strong version. The blue sea gets its color by reflecting the light coming from the blue sky. As we have seen, very few objects get their color in this way, and we may well think that the sea is not blue as it is in itself essentially because of the mechanism through which the sea changes colors. We have not yet been given a reason to think that the considerations that make us say that the sea does not have its color as it is in itself apply to all other objects. ${ }^{18}$ On the face of it, these considerations only apply to objects that have their colors by reflection.

If we are to generalize our results, alexandrite offers us a better stepladder. Alexandrite, you will recall, closely resembles emeralds and rubies in the way that its colors are chemically grounded. In all three gems, a chromium impurity in an otherwise clear background mass absorbs light. Chemistry does not explain why Alexandrite changes color. Its variety, in Nassau's words, “occurs as a psychophysical phenomenon derived from the specific response characteristics of the human eye-brain combination to the different illuminations" (p. 89). Chemically and physically speaking, the three gems are cousins; they differ in chemistry sufficiently to differ in appearance, but one might think that they are too physically similar to possess their colors in different ways.

\footnotetext{
${ }^{17}$ In fact, it is hard to fit the implicit doctrines of the porphyry argument with Locke's position that motion is a primary quality. I do not want to go into the matter here, but I believe that these doctrines entail that motion does not belong to objects as they are in themselves.

18 According to an anonymous ancient commentator on the Theaetetus, pyrrhonists argue that "neither shape, nor sounds, nor things tasted, smelled, or touched, or anything else perceived, has its own properties; for if these things were the same, they would not affect us differently because of distances or things seen along with them, just as we are impressed differently by the sea according to the states of the air" (Hankinson 1995, 138). The commentator does not quite attribute to the pyrrhonists the following particularly strong uniformity principle: if the colors of the sea do not belong
} 
Even here, it is not clear why this physical similarity should reflect a metaphysical similarity. Of course, if we did decide that emerald, alexandrite, and ruby cannot be so physically similar while emeralds and rubies alone have their colors as they are in themselves, it is far from obvious that uniformity demands that we change our minds about whether red and green belong to emeralds and rubies as they are in themselves instead of just conceding that alexandrite is really green as it is in itself (or really red as it is in itself). That is, even if we could justify some sort of uniformity thesis, it is not clear how we should apply it.

If every object's color could be changed in a mere Cambridge change, then, by the Cambridge principle, it would follow that colors do not belong to objects as they are in themselves. Indeed, some philosophers believe that every colored thing can change color without really changing. According to Locke, everything will lose its color if all sentient creatures go out of existence (2.31.2). According to Jonathan Bennett, $(1968,105-06)$ everything will change its color if diabolical surgeons operate on everyone's optic nerves. According to Edward Averill, (1992, 55455) anything will change its color if the right gas settles in the Earth's atmosphere. However, these are controversial propositions not entailed by anything in Locke's porphyry argument.

It would be interesting to end up with the mixed position that some things possess colors as they are in themselves and some things do not. For one thing, if the very same color, green, could belong to emeralds as they are in themselves and not belong to alexandrite as it is in itself, that would show that belonging to a body as it is in itself is a fact about the way a color inhere in that body and not an intrinsic fact about the color itself. That is to say, belonging-to-bodies-as-they-are-inthemselves would not be a feature that belongs to colors as they are in themselves.

to it as it is in itself, then no perceptible quality belongs to any body as it is in itself. The sea is merely an example intended to illustrate a wider phenomenon. 
I am not sure if this mixed position is the one to adopt. I have tried to show that some colors do not belong to some objects as they are in themselves. Whether any color belongs to any object as it is in itself strikes me as a very difficult question. At any rate, besides raising difficult questions, Locke's argument is an ingenious use of important principles. Related arguments are sound and reach interesting conclusions. I had these questions, principles, and conclusions in mind when I promised that Locke's porphyry argument was worth careful scrutiny. ${ }^{19}$

\section{Department of Philosophy}

University of Massachusetts, Amherst

\footnotetext{
${ }^{19}$ I thank John Carriero, Andrew Hsü, Rogers Albritton, Sam Rickless, Seana Shiffrin, Tony Martin, Alex Rajczi, Larry Lombard, Lisa Shapiro, Glenn Branch, Amy Kind, Eric Wing, Mark Rubin, and Dominik Sklenar for helpful comments. I presented this material in talks at UCLA and at the University of Massachusetts. I thank those audiences for their questions and comments. I thank Sarah Gibson for learned inquiry into the color of light bulbs, Frank Tepley for a useful conversation on the geology of porphyry, and Bourget Brothers Building Materials for providing me with a sample of the stone.
} 


\section{References}

Alexander, Peter. (1985) Ideas, Qualities, and Corpuscles: Locke and Boyle on the External World, Cambridge: Cambridge University Press.

Anscombe, G. E. M. (1981) "The Subjectivity of Sensation," in Metaphysics and the Philosophy of Mind, vol. 2 of her Collected Philosophical Papers, Minneapolis: University of Minnesota Press.

Averill, Edward. (1992) “The Relational Nature of Color,” Philosophical Review, 101: 551-88.

Ayers, Michael. (1981) “Mechanism, Superaddition, and the Proof of God's Existence in Locke’s Essay', The Philosophical Review 90: 210-251.

Ayers, Michael. (1991) Locke, 2 vols., London: Routledge.

Ayers, Michael. (1997) Review of The Cambridge Companion to Locke, The Locke Newsletter 28: 157-189.

Bacon, Francis. (1620/1960) “The Great Instauration,” in The New Organon and Related Writings, edited by Fulton Anderson, and translated by James Spedding, Robert Leslie Ellis, and Douglas Denon Heath, New York: Macmillan Publishing Co.

Bennett, Jonathan. (1968) "Substance, Reality, and Primary Qualities," in Locke and Berkeley: A Collection of Critical Essays, edited by C. B. Martin and D. M. Armstrong, Garden City, New York: Anchor Books.

Bolton, Martha Brandt. (1983) “Locke and Pyrrhonism: The Doctrine of Primary and Secondary Qualities," in The Skeptical Tradition, edited by Myles Burnyeat, Berkeley and Los Angeles: University of California Press.

Geach, Peter. (1968) "What Actually Exists," in God and the Soul, London: Routledge and Kegan Paul.

Geach, Peter. (1972) “God's Relation to the World,” in Logic Matters, Berkeley and Los Angeles: University of California Press. 
Guerlac, Henry. (1986) "Can There be Colors in the Dark? Physical Color Theory before Newton," Journal of the History of Ideas, 47: 3-20.

Hankinson, R. J. (1995) The Sceptics, London: Routledge.

Hardin, C. L. (1988) Color for Philosophers, Indianapolis: Hackett Publishing.

Jackson, Frank and Robert Pargetter. (1987) “An Objectivist’s Guide to Subjectivism about Colour," Revue Internationale de Philosophie, 41: 127-41.

Jacobs, Struan and Allan McNeish. (1997) “Locke, McCann, and Voluntarism”, Pacific Philosophical Quarterly 78: 349-362

Locke, John. (1689/1975) An Essay Concerning Human Understanding, edited by Peter Nidditch, Oxford: Oxford University Press.

Lombard, Lawrence Brian. (1986) Events, London: Routledge and Kegan Paul.

McCann, Edwin. (1983) "Lockean Mechanism," in Philosophy: Its History and Historiography, edited by A. J. Holland, Dordrecht: D. Reidel.

McCann, Edwin. (1994) “Locke’s Philosophy of Body," in The Cambridge Companion to Locke, edited by Vere Chappell, Cambridge: Cambridge University Press.

Milton, J. R. (1983) “Lockean Mechanism: A Comment," in Philosophy: Its History and Historiography, edited by A. J. Holland, Dordrecht: D. Reidel.

Nassau, Kurt. (1983) The Physics and Chemistry of Color: The Fifteen Causes of Color, New York: John Wiley and Sons.

Plato. (1990) Theaetetus, translated by M. J. Levett and edited by Myles Burnyeat, Indianapolis: Hackett.

Quine, Willard Van Orman. (1980) "On What There Is," in From a Logical Point of View, 2nd ed., Cambridge, Mass.: Harvard University Press. 
Rickless, Samuel C. (1997) “Locke on Primary and Secondary Qualities," Pacific Philosophical Quarterly, 78: 297-319.

Sandøe, Peter. (1988) “Secondary Qualities_-Subjective and Intrinsic," Theoria, 54: 200-19.

Smith, Terence Paul. (1973) “On the Applicability of a Criterion of Change," Ratio, 15: 325-33.

Stuart, Matthew. (1996) “Locke’s Geometrical Analogy”, History of Philosophy Quarterly 13: 451-467.

Webster's Ninth New Collegiate Dictionary. (1983) Springfield, Mass.: Merriam-Webster.

Wilson, Margaret. (1979) “Superadded Properties: The Limits of Mechanism in Locke," American Philosophical Quarterly 16: 143-150.

Wilson, Margaret. (1982) “Superadded Properties: A Reply to M. R. Ayers," The Philosophical Review 91: $247-252$.

Woozley, A. D. (1964) “Introduction," in An Essay Concerning Human Understanding, by John Locke, edited by A. D. Woozley, London: Collins. 